\title{
SOCIO-EDUCATIONAL E-LEARNING PLATFORM - PROPOSITION
}

\author{
Emir Pećanin ${ }^{1 *}$, \\ Siniša llić2 \\ Bojana Milosavljević3 \\ Bratislav Mirić1, \\ Edin Dolićanin ${ }^{1}$
}

\author{
${ }^{1}$ State University Novi Pazar, \\ Novi Pazar, Serbia \\ ${ }^{2}$ Faculty of Technical Science Kosovska \\ Mitrovica, \\ Kosovska Mitrovica, Serbia \\ ${ }^{3}$ Singidunum University, \\ Belgrade, Serbia
}

\begin{abstract}
:
Universities rely on some kind of learning management system (LMS) for distribution of lecture recourses, books, video tutorials etc. Such systems are usually incorporated and work along with the traditional teaching methods to create a cohesive learning environment for students. Unfortunately, we are not always successful in creating such environments. Being unable to completely integrate IS (information system), e-learning system and LMS systems, and the lack of adequate communication components in those systems, results in diminishment of social interactions between teachers and students. That means that students have to rely on some other form of communication medium, usually social networks, to be able to interconnect, create social groups and interact. Social networks enable proper group organization and real-time communication between students. The proposed platform will try to create a correlation between the IS, the e-learning system giving it social network aspect and enabling direct, two-sided and transparent communication between students, teachers and university administration.
\end{abstract}

Key words:

CMS, LMS, educational system, social network.

\section{Acknowledge}

This paper has been supported by the Ministry of Education, Science and Technological Development of the Republic of Serbia, as a part of the projects ON171007 and TR35026.

\section{INTRODUCTION}

Modern web technologies, web-blogs, and wiki pages have allowed easy and efficient integration of e-learning into traditional teaching methods. As a result, universities rely on online repository, contend management system (CMS) or LMS for distribution of lecture materials.

Al-Qahtani and Higgist (2013) showed that mixed teaching methods that incorporate traditional and e-learning methods, yielded much better results than its individual components. Traditional and e-learning methods gave almost the same results when compared individually, but worse results when compared to mixed teaching methods.

Interactivity, simplicity, and social aspect - being able to exchange opinions with one's peers, allowed very fast growth of social networks. Today, usability of social networks goes far beyond a simple chat service.
Correspondence:

Emir Pećanin

e-mail:

epecanin@np.ac.rs 
EdX, Udacity, Udemy and other e-learning platforms, use a similar approach by fully utilizing the social aspect of the platform to increase interactivity, attract new users and increase interest in learning.

In this paper, we will give a proposition for creation of an e-learning platform that places special emphasis on students, teachers, interactivity and social interaction. The platform is expanded with administrative tools and database management tools. We will present a structured plan, role, and page organization and propose technologies that can be used in its creation.

\section{PROPOSED TECHNOLOGIES}

\section{CMS \& LMS}

E-learning platforms can be described as modular content management systems (CMS). Modularity of such systems allows expansion of its features by installing or writing various plugins. The degree of modularity is defined by its creator, platform capabilities, and plugin complexity. If such systems are incorporated in an educational system, they are usually called LMS (learning management systems). A popular example of such a system is Moodle which is currently used by more than 30000 institutions across the world (Cole and Foster, 2009).

Unfortunately, certain features are simply impossible to implement in such platforms. Functionalities are either too expensive to implement or the LMS system cannot support such features. On the other hand, even the well-rounded systems are not used to their maximum potential. In the worst case scenario, such systems become web-pages additions where students can find and download latest lecture notes, practice examples and nothing else. Such systems even include rudimentary chat system that enables its users to send and receive messages but aren't used that much. Students and teachers tend to use e-mail clients.

Modern CMS systems, even if not originally intended for educational purposes, are flexible enough and can be excellent starting point for the creation of educational platforms.

No CMS can claim to be the best CMS system. We propose two reliable and stable CMS systems.

- Drupal - very flexible and adaptable CMS system. Very popular with frontend and backend engineers. Drupal has certain characteristics of PHP framework and is usually referred to as CMF - Content Management Framework.
The only flaw of this system is its complexity. Drupal is not very user friendly towards new users.

- Wordpress - started as blogging CMS. Today, Wordpress evolved into powerful CMS system. Simplicity, large user base and numerous plugins, allowed Wordpress to be used for development of complex web applications. Wordpress based applications and web pages tend to look all the same.

The usefulness of CMS systems becomes evident in situations where applications require web page structure. The fundamental flaw of CMS system is their plugin dependency. Each feature requires one more plugin to be installed. This tends to become a problem if number of installed plugins becomes too large. Instead of features, the CMS becomes overloaded with excessive plugins which contain unnecessary code degrading its performance e.g. for basic webpage functionalities Wordpress requires at least five plugins installed.

\section{PHP Framework}

PHP based Framework for application development is a popular approach that gives engineers absolute freedom when choosing what features to include in their system. This approach requires trained app designers and programmers, whereas CMS systems are not so demanding. In general, the consensus is that PHP framework is good as long as it has a dedicated team that keeps up with modern trends. According to last year's survey (Skvorc, 2015), Laravel PHP platform took first place (Figure 1). Laravel is one of the youngest PHP libraries. Customizability and flexibility made it top choice for app development (Rees, 2015).

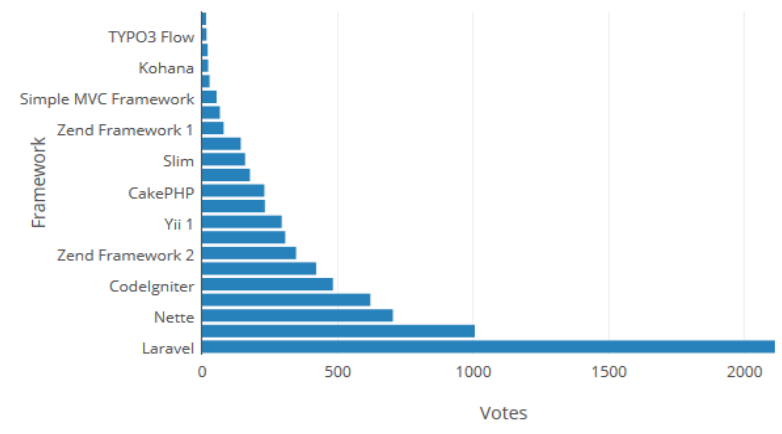

Figure 1. Popularity diagram based on survey from 2015. 
PHP framework will take care of any computational tasks (back end) of our platform. We have several choices regarding the front end of our platform, HTML and CSS combination, Bootstrap or AngularJS.

For One page applications and web pages, the best choice is AngularJS. One page design is practical in a sense that it reduces number of HTML calls towards the server (Pitt, 2014).

\section{Database}

Since the proposed e-learning platform is a clientserver, web orientated application, it will use a MySQL database. The structure of the database can be organized from scratch or, if university IS already uses one, can be adapted to existing database.

\section{DESCRIPTION OF THE APPLICATION}

The proposed application expands exiting features of a high-end LMS system in which teachers can organize the teaching curriculum, organize lecture material, test organization and creation, expanding it with a social network aspect. The application will have a built-in chat system and user profile pages with wall panels where teachers and students can pin messages and class notifications. For administrative staff a special panel would be created where they can control the flow of information and manage user roles.

There are five types of user profiles:

- Administrator - has complete control over the system.

- Clerk - can organize students and exam applications, has access to exam schedule and student report cards.

- Teacher - can create course pages, upload and edit lecture material on their own pages, create and organize test pages for his courses, can access subscribed student lists and edit them. Teachers can create chat rooms for Q\&A sessions, but this profile type requires registration. This profile type requires registration.

- Student - can be a subscriber to a course, can download and comment on a course. Profile has access to chat seasons for subscribed courses. Can chat with other users and post messages on wall panels, his own and other user's walls. Profile type that requires registration.

- Guest - profile type that doesn't require registration, can see the overview of the course but cannot access its contents.
In terms of profile privileges, Teacher has all privileges of the Student profile, and Student has all privileges of Guest profile. Vice versa does not apply. Users with profile type Clerk are added by administrator directly so registration is not required. Administrator type profile is created with the creation of the platform database.

\section{User pages}

The base page of application is administrative panel, acessible only by the Administrator profile. The Clerk user profile can access certain categories of this panel. These user profiles don't require registration to allow use of the platform. For profiles Teacher and Student registration is mandatory. Teachers and students that are already in IS of the university will receive accounts generated by the system. Useranemes of the existing accounts are generated by the first letter of the name and a complete string of the surname e.g. Emir Pecanin would be epecanin. Passwords are randomly generated and emailed to the users. Once logged in, these users can change the password using their profile pages. Since the platform is open for registration, all new users can create new accounts by filling in registration form. Not all the users have their profile pages.

Administrator \& Clerk profiles - Category organization of the Administrative panel can change depending on the needs of the institution. Design and organization of the panel should prioritize modularity and clean presentation of the information. We based our design on the dashboard of the popular CMS system. The overview page is shown in Figure 2. Basic information, navigation menu are common page components, we have included statistics, activities and date - task organization panel. The Clerk profile can access student category where they can organize and change student information, print reports and student related documents. This profile can access the sub-category Exam halls where they can organize exams by course or by available classrooms.

Teacher profile - Can create, edit and organize courses. Can organize student lists, edit marks and define course regulations. Both Teacher and Student profiles have wall panels where they can pin messages. Both Teacher and Student have Subjects link that leads them to the course list. For the Teacher profile it will show the list of courses user teaches and for students it will show the list of courses they subscribed to. Teacher and Student profiles have access to chat panels where they can communicate with other users and search panel they can use to find courses and other users that are in 
the database. Both profiles have organization panels on their profile page where they can create To do lists and see what events are scheduled during the week currently shown in Figure 2.

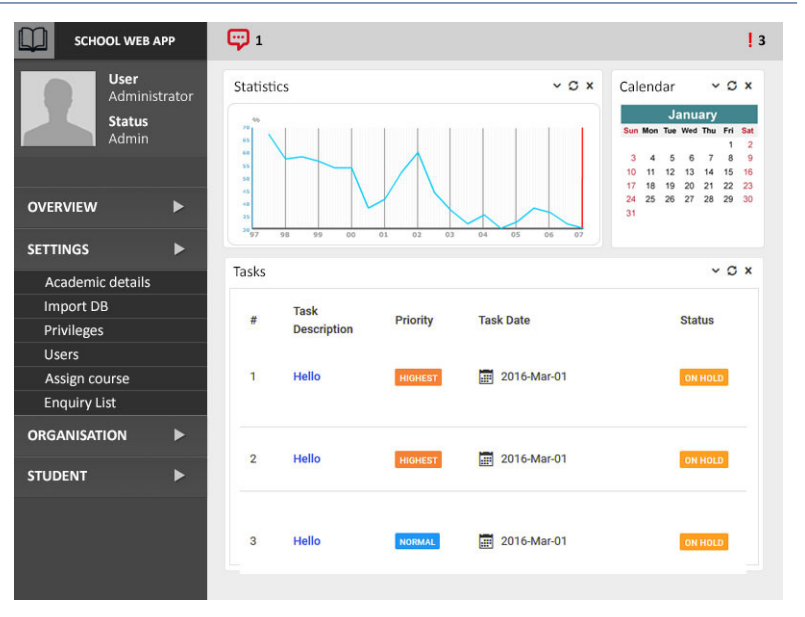

Figure 2. Overview page

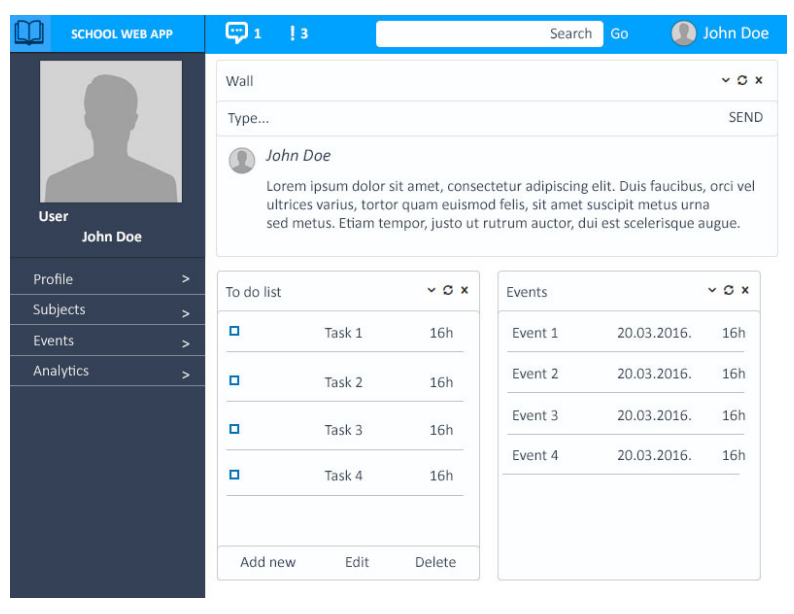

Figure 3. Profile page

\section{LOGIC DESIGN}

\section{Access form}

Users can gain access to the application using the access ( $\log$ in) form. Input of username and password is required. Depending of what user profile they are assigned to, the application will show different pages. Administrator and Clerk profiles will see the page shown on Figure 2. Teacher and Student profiles will be shown Figure 3.

The form has a Guest button for the Guest profile users that will be shown as a generalized Figure 3 page excluding personal info, To do list and the ability to write on the wall panel.

\section{Registration form}

The registration form contains the following fields:

- E-mail address,

- Name,

- Surname,

- Username,

- Password,

- Repeat password,

- Year of birth.

All newly created user accounts are assigned to the Student user profile until the administrator reassigns them. The password needs to be at least 8 characters long combining lowercase and uppercase letters, and number. The application will notify the user if any error occurs. In case users leave part of the form empty, form will halt the creation of the account until the user enters all required information.

Once registration is complete, the user will receive an email message containing the validation link that will ensure that their email was input correctly.

\section{Profile page}

Requires input of additional information:

- Home town

- In case of Student profile

- Department

- Study program

- Index number

- Year of enrollment

- In case of Teacher profile

- Department

Information isn't mandatory but it is needed for the profile completion. In case the user does not fill in additional information, a message will appear in the header of the profile page requesting him to do so.

The Administrator profile page controls all functions of the application. The category list of administrative panel is given in Table 1.

Profile pages Teacher and Student contain the following links:

- Profile page - user profile page that contains basic user information. Users can write on the wall panel and share messages and notifications with other users. The page contains an event list panel and user account settings. The settings also include options where users can delete their own account. 


\begin{tabular}{|c|c|c|c|}
\hline Category & I level & II level & Description \\
\hline Overview & - & - & $\begin{array}{l}\text { Basic information and stastistics regarding students, student grades, number of } \\
\text { active courses, diagram containing information about student presence }\end{array}$ \\
\hline \multirow{6}{*}{ Settings } & $\begin{array}{l}\text { Academic } \\
\text { details }\end{array}$ & - & Setting begin and end date of the semster \\
\hline & Import DB & - & Used for importing and exporting data from external database \\
\hline & Privileges & - & Used for defining user group privileges \\
\hline & Users & & $\begin{array}{l}\text { Tabelar representation of user information, can be displayed and organised by } \\
\text { certain condition }\end{array}$ \\
\hline & Assign course & - & Used for asigning courses to users \\
\hline & Enquiry List & - & $\begin{array}{l}\text { Displays registered user list, used for accepting or declining user registration } \\
\text { (usually for bot detection and removal) }\end{array}$ \\
\hline \multirow{16}{*}{ Organisation } & \multirow{2}{*}{$\begin{array}{l}\text { Course and } \\
\text { allocation }\end{array}$} & Course & Defining student program regulations \\
\hline & & $\begin{array}{l}\text { Teacher al- } \\
\text { location }\end{array}$ & Used for reogranisation of teachers \\
\hline & \multirow{3}{*}{ Subjects } & Subjects & Creating new courses, defining course regulations \\
\hline & & $\begin{array}{l}\text { Assign sub- } \\
\text { jects }\end{array}$ & Used for subject assignment \\
\hline & & Sub. allocation & Used for allocation of teachers on existing courses \\
\hline & $\begin{array}{l}\text { Lession Plan- } \\
\text { ning }\end{array}$ & Plan & Used for creating, editing and organising course curriculum \\
\hline & \multirow{6}{*}{ Exams } & Create exam & Used for creating course exams \\
\hline & & $\begin{array}{l}\text { Set Grade } \\
\text { scale }\end{array}$ & Used for setting grade scales \\
\hline & & $\begin{array}{l}\text { Set Credit } \\
\text { point }\end{array}$ & Used for defining credit points for each activity \\
\hline & & Set exam & Setting date for exams \\
\hline & & Broad sheet & Generates table containing exam results based on subject \\
\hline & & Report card & Generates course list and result achieved during the semester \\
\hline & \multirow{3}{*}{ Exam hall } & Exam hall & Used for organization of the exam halls \\
\hline & & $\begin{array}{l}\text { Hall arrange- } \\
\text { ments }\end{array}$ & Exam hall organization \\
\hline & & Invigilators & Used for assignement of invigilators to the exams or exam halls \\
\hline & Circular & - & $\begin{array}{l}\text { Used for circular messaging and sending global notifications (usually for } \\
\text { system updates) }\end{array}$ \\
\hline \multirow{5}{*}{ Students } & Category & - & Student category organization \\
\hline & Admission & - & Used for adding new students to database \\
\hline & Student List & - & $\begin{array}{l}\text { Tabelar representation of students according to year, student program or } \\
\text { department }\end{array}$ \\
\hline & Attendance & - & $\begin{array}{l}\text { Tabelar representation and statistics of student attendance according to course, } \\
\text { year, student program and department }\end{array}$ \\
\hline & Print list & - & Used for generating student info reports, grade reports or course reports \\
\hline
\end{tabular}

Table 1. Navigation categories for Administrator user profile

- Subjects page - shows the course page. The Teacher and Student user profiles will have different composition of this page. For the Teacher profile it will show the list of courses the user is teaching. For the Student profile it will show a list of subscribed subjects.

- Event page - shows a tabular schedule of events during the current week and includes extra information for each event.
- Analytics page - shows student statistics, course attendance, students grade statistics etc. This page includes graphical representation based on these values.

Profile pages also include a chat system similar to the one popular social platforms use. Wordpress based applications can use plugin called ChatPirate.

The best solution is to develop the chat system ourselves. This way we can add all the features we need and 
ensure that security of our webpage isn't compromised by installing the third party software.

The lectures have term based organization where every term contains fields where the Teacher profile can upload his lecture materials. The Teacher profile can edit, delete or hide uploaded lectures. Initially only the first term will be available. As soon as Teacher profile uploads some material, second term is shown with empty fields. Student profiles cannot see empty term fields on their pages. The application supports most of the popular video and audio formats as well as textual file format. Since the number of courses and lecture material will continue to grow, we must ensure that our server's hard drive capacity can store all of the uploaded data.

Term fields have comment panels where students can discuss lectures, give suggestions or remarks.

The Teacher profile can organize tests for the subscribed students. Generating a test is an automatized process defined by the application. Teachers need to fill in the question, one or more correct answers and one or more incorrect answers. Students can apply for tests. The application randomly generates tests using questions that the Teacher profile provided and grade students based on correct and incorrect answers. Tests are time restricted.

The Clerk profile manages student information, exams and student statistics. This profile can also manage Exam halls and generate and print report and grade cards for students.

The Guest profile can only access the course list. They can also see what terms are already uploaded on the application but cannot download or read files until they create an account.

\section{CONCLUSION}

Combining traditional teaching methods and elearning methods has improved reception of knowledge and the quality of knowledge transferred to students. Yet, these systems are far from perfect. With great effort we try to perfect, invent and re-invent methods to increase the quality of lectures and transmission of knowledge.

This paper proposes the plan of elegant, robust and modular e-learning platform. The platform will upgrade outdated solutions where IS of the university, traditional teaching methods and communication systems are individualized and physically separated. We gave guidelines for its realization in hope that the platform will become a connecting bridge between teachers and students and improve communication between them.

\section{LITERATURE}

Al-Qahtani, A.A.Y., Higgist, S.E. (2013), Effects of traditional, blended and e-learning on students' achievement in higher education, Journal of Computer Assisted Learning, Vol. 29, 220-234 DOI: 10.1111/j.1365-2729.2012.00490.x

Cole, J., Foster, H. (2009). Using Moodle: Teaching with the Popular Open Source Course Management System, Sebastopol: O'Reilly Media, Inc.

Skvorc, B. (2015) Best PHP framework for 2015: SitePoint Survey Results. Retrieved March 20, 2016, from http://www.sitepoint.com/best-php-framework2015-sitepoint-survey-results/

Rees, D., Petrović, S., Laguna A. (2015). Laravel: Code Bright. Retrieved Marcch 20, 2016, from LeanPub

https://leanpub.com/codebright

Pitt ,C., Otwell, T. (2014). Laravel 4 Cookbook, Retrieved Marcch 20, 2016, from LeanPub

https://leanpub.com/laravel4cookbook 